\title{
DETECTION OF GROUP A STREPTOCOCCI IN THROAT CULTURES BY IMMUNOFLUORESCENCE
}

\author{
John J. Redys, B.S., Arline B. Parzick, B.S., and Earle K. Borman, M.S.
}

A FLUORESCENT antibody (FA) technique used by the Connecticut State Department of Health laboratories for serologic identification of group A streptococci was described in 1960 (1). Since then changes in routine methods have been instituted in our laboratories which contribute materially to ease of handling of large numbers of throat cultures.

Our original technique required two-step inhibition of common antigen fluorescence to eliminate cross-reactions with groups $\mathrm{C}$ and $(\mathrm{x}$ streptococci. Subsequently, conjugates labeled with improved batches of fluorescein isothiocyanate yielded staining reagents of higher titer and greater staining intensity than those made from batches available when our first studies were made. For example, conjugates prepared during and after 1960 have consistently yielded titers of $1: 400$ or higher compared with titers of $1: 40$ of conjugates prepared with dyes available before and during 1959. Availability of more potent reagents has led us to the use of a one-step inhibition technique whereby specific staining of group A streptococci is accomplished with a reagent prepared from antigroup A conjugate sorbed with group $\mathrm{C}$ cells and then combined with anti-group $\mathrm{C}$ serum.

The one-step inhibition technique and a slight modification of our original culture procedure have simplified the routine processing of more than 50,000 cultures annually, with daily loads ranging from 100 to 700 . Studies leading to the adoption of our current procedure and a description of it follow.

\section{General Methods}

Antiserums were prepared in rabbits by conventional immunization schedules using formalin-killed streptococci. $\quad$.ll antiserums were checked for reactivity by conventional precipitin test against homologous organism extracts, although no specific precipitin titer was demanded.

Globulin fractions were prepared from antiserums by $\left(\mathrm{NH}_{4}\right)_{2} \mathrm{SO}_{4}$ precipitation (2). Conjugates of globulins with fluorescein isothiocyanate were prepared (3) using a ratio of 0.05 $\mathrm{mg}$. dye to each $1.0 \mathrm{mg}$. protein in the globulin fraction. Conjugates were merthiolated $(1: 10,000)$ and stored in convenient amounts at $-200^{\circ} \mathrm{C}$. Conjugates so stored have retained their reactivity for at least 1 year. Once thawed, conjugates were not refrozen. We recommend storage of undiluted conjugate in small aliquots so that only the amounts necessary for 2 to 3 months' use are thawed, sorbed, and diluted as needed.

Conjugates were sorbed without prior dilution for 1 hour at $35^{\circ} \mathrm{C}$. with an equal volume of packed cells previously washed 3 times with 0.01 molar phosphate buffered saline, $\mathrm{pH}$ 7.4. Streptococcal strains used for sorptions were formalin killed (4); staphylococcal sorbing strains were used live $(5,6)$. Sorbed conjugates must be freed entirely of sorbing cells by centrifugation. After sorption, we recommend that conjugates be diluted $1: 10$, merthiolated $1: 10,000$, dispensed in 1- to $2-\mathrm{ml}$. amounts, and stored in a refrigerator. The final $\mathrm{FA}$ reagent can be prepared by removing small amounts as needed.

FA staining was performed on smears made from appropriate 18- to 24 -hour broth cultures

Mr. Redys is a supervising microbiologist; Mrs. Parzick, a principal microbiologist; and Mr. Borman, director of the laboratory division, Connecticut State Department of Health, Hartford. 
(Todd-Hewitt or Streptosel). Air-dried and heat-fixed smears were stained by flooding with appropriate conjugates for 20 minutes in a moist chamber followed by a 10-minute rinse in buffered saline (pH 7.2-7.4). Stained smears were mounted in buffered glycerol under coverslips and examined on a dark-field microscope in an optical assembly using HBO 200 mercury vapor bulb with $B(\div 12$ pass filter and $O G \quad 1$ barrier filter or with $\mathrm{CG} 1$ pass filter and Euphos barrier filter.

\section{Experimental Procedures}

When conjugates more potent than those used in our previous work (1) were used unsorbed with the two-step inhibition technique, results were not so clearcut as with conjugates of low potency. Consequently, further sorption studies were undertaken.

Sorption of potent group I conjugates was carried out with three streptococcal group C strains and two coagulase-positive staphylococcal strains. Table 1 shows the results of sorption in terms of intensities of homologous and heterologous staining and of resultant FA titers. All sorptions were single except for that shown in the last column. None of the sorbed aliquots was satisfactory. Some remained nonspecific; others became impaired, even ineffectual, staining reagents. Further experiments (not tabulated) showed that neither doubling of sorption time nor the use of repeated sorptions was more effective.

Further investigation of the conjugates sorbed with group ( showed that they were made specific for group A by either a two-step or a one-step inhibition or blocking technique using group $C$ antiserum in suitable dilution. For ease of handling, the one-step inhibition technique $(7,8)$ was selected for further investigation. Four different staining reagents prepared from the same group A conjugate $(1: 40)$ were used on routine isolates to achieve the results shown in table 2. The unsorbed conjugate contained antibodies for streptococcal groups $C$ and $G$ and for staphylococci which were only partially removed by sorption with group C cells. However, complete inhibition of significant cross-reactions was achieved by the addition of antiserum for group C. In one trial the addition of normal rabbit serum eliminated cross-reactions with staphylococci only, a function performed equally well by use of the group (c antiserum. However, there is evidence (personal communication from M. I). Moody), which we have recently confirmed, that many normal rabbit serums contain sufficient antibody against groups $C$ and $(x$ to make them effective inhibitors of the common cross-reactions.

Further studies on the inhibiting potency of the group (C antiserum are shown in table 3 . Although reasonably effective inhibition was

\section{Table 1. Effect of sorption of group A conjugate with selected heterologous strains on staining}

intensities and homologous titers

\begin{tabular}{|c|c|c|c|c|c|c|c|}
\hline \multirow[b]{2}{*}{ Strains stained with $1: 20$ conjugate } & \multicolumn{7}{|c|}{ Strains used to sorb group A conjugate } \\
\hline & Unsorbed & $\begin{array}{l}\text { Strepto- } \\
\text { coccus } \\
\text { group } \mathrm{C}, \\
\text { No. } 2\end{array}$ & $\begin{array}{l}\text { Strepto- } \\
\text { coccus } \\
\text { group C, } \\
\text { No. } 3\end{array}$ & $\begin{array}{l}\text { Strepto- } \\
\text { coccus } \\
\text { group C, } \\
\text { No. } 4\end{array}$ & $\begin{array}{c}\text { S. aureus, } \\
\text { No. } 1\end{array}$ & $\begin{array}{l}\text { S. aureus, } \\
\text { No. } 2\end{array}$ & $\begin{array}{l}\text { Strepto- } \\
\text { coccus } \\
\text { group C, } \\
\text { No. } 2 \text {, and } \\
\text { S. aureus, } \\
\text { No. } 1\end{array}$ \\
\hline $\begin{array}{l}\text { Streptococcus group A, No. 1.. } \\
\text { Streptococcus group C, No. 2. } \\
\text { Streptococcus group C, No. } 3 \\
\text { Streptococcus group C, No. 4 } \\
\text { Streptococcus group G, No. } 5 \\
\text { Staphylococcus aureus, No. } 1 \\
\text { Staphylococcus aureus, No. 2 }\end{array}$ & $\begin{array}{l}4 \\
4 \\
4 \\
4 \\
4 \\
4 \\
4\end{array}$ & $\begin{array}{l}4 \\
3 \\
3 \\
4 \\
3 \\
4 \\
4\end{array}$ & $\begin{array}{l}4 \\
4 \\
3 \\
4 \\
3 \\
4 \\
4\end{array}$ & $\begin{array}{l}4 \\
3 \\
4 \\
3 \\
3 \\
4 \\
4\end{array}$ & $\begin{array}{r}3 \\
3 \\
3 \\
3 \\
0-2 \\
0-2 \\
0-2\end{array}$ & $\begin{array}{l}4 \\
4 \\
4 \\
4 \\
4 \\
4 \\
4\end{array}$ & $\begin{array}{l}0-2 \\
0-2 \\
0-2 \\
0-2 \\
0-2 \\
0-2 \\
0-2\end{array}$ \\
\hline Homologous titer after sorption..... & $1: 400$ & $1: 200$ & $1: 200$ & $1: 200$ & $1: 20$ & $1: 400$ & $\begin{array}{r}\text { Less than } \\
1: 20\end{array}$ \\
\hline
\end{tabular}

Note: $4=$ brilliant; $3=$ strong but not maximum; $0-2=$ none to low intensity. 
achieved when group $C$ antiserum was diluted $1: 80$ or $1: 160$ in the $1: 40$ group $A$ conjugate, a dilution of $1: 10$ was the most effective and it did not diminish specific staining of group $A$ strains.

Theoretically, an excess of inhibiting antibody has some value and it does not interfere with specific sensitivity. Therefore, to develop a specific group A fluorescent antibody staining reagent from materials with titers of the order of those reported (table 3), we recommend a mixture of 1 volume of group $C$ ant iserum with 9 volumes of group $A$ conjugate diluted no more than one-tenth its homologous FA titer. The less dilute the conjugate, the greater the keeping quality of the staining reagent. By this means, $\mathrm{FA}$ reagent highly specific for group $A$ streptococci can be prepared consistently and easily. We caution against the preparation of too large a quantity of reagent at one time; we routinely prepare a 2 -weeks' supply.
The specificity and sensitivity of a reagent prepared as recommended above have been evidenced in our routine work. I)uring one 12month period, 7,051 group A streptococci were identified by the FA technique. A random sampling of 10 percent ( 705$)$ of these strains showed complete specificity when checked by conventional group precipitin methods. Conversely, 1,795 beta hemolytic streptococci isolates nonreactive to the $\mathrm{FA}$ reagent for group A were all negative to the group A precipitin test. Of these latter isolates, 520 were of groups $\mathrm{C}$ and $\mathrm{G}$.

Practical evaluations of this reagent have been made in the central public health laboratories of Hawaii, Kansas, North Carolina, South Dakota, and the Virgin Islands. Informal reports uniformly stated that staining of group A streptococci was bright and distinct and that there were no confusing or false results.

Table 2. Effect of sorption and one-step inhibition on FA specificity of group A conjugate

\begin{tabular}{|c|c|c|c|c|c|c|c|c|c|c|c|c|}
\hline \multirow{3}{*}{ Staining reagent } & \multicolumn{12}{|c|}{ FA staining intensities with routine isolates } \\
\hline & \multicolumn{3}{|c|}{$\begin{array}{l}\text { Streptococcus } \\
\text { group A, } 25 \\
\text { strains }\end{array}$} & \multicolumn{3}{|c|}{$\begin{array}{l}\text { Streptococcus } \\
\text { group C, } 25 \\
\text { strains }\end{array}$} & \multicolumn{3}{|c|}{$\begin{array}{l}\text { Streptococcus } \\
\text { group G, } 10 \\
\text { strains }\end{array}$} & \multicolumn{3}{|c|}{$\begin{array}{l}\text { Staphylococcus } \\
\text { aureus, } 10 \\
\text { strains }\end{array}$} \\
\hline & 4 & 3 & $0-2$ & 4 & 3 & $0-2$ & 4 & 3 & $0-2$ & 4 & 3 & $0-2$ \\
\hline $\begin{array}{l}\text { Group A conjugate unsorbed } \\
\text { Group A conjugate sorbed with group C cells } \\
\text { Group A conjugate sorbed as above (9 vol.) plus } \\
\text { group } \mathrm{C} \text { antiserum (1 vol.) } \\
\text { Group A conjugate sorbed as above }(9 \mathrm{vol}) \text { plus } \\
\text { normal rabbit serum (1 vol.) }\end{array}$ & $\begin{array}{l}25 \\
25 \\
25 \\
25\end{array}$ & $\begin{array}{l}0 \\
0 \\
0 \\
0\end{array}$ & $\begin{array}{l}\mathbf{0} \\
0\end{array}$ & $\begin{array}{r}25 \\
8 \\
0 \\
8\end{array}$ & $\begin{array}{r}0 \\
10 \\
0 \\
10\end{array}$ & $\begin{array}{r}0 \\
7 \\
25 \\
7\end{array}$ & $\begin{array}{r}10 \\
1 \\
0 \\
1\end{array}$ & $\begin{array}{l}0 \\
1 \\
0 \\
1\end{array}$ & $\begin{array}{r}0 \\
8 \\
10 \\
8\end{array}$ & $\begin{array}{r}10 \\
10 \\
0 \\
0\end{array}$ & $\begin{array}{l}0 \\
0 \\
0 \\
0\end{array}$ & $\begin{array}{l}\mathbf{0} \\
\mathbf{0}\end{array}$ \\
\hline
\end{tabular}

Note: $4,3,0-2=$ degree of fluorescence as in table 1.

Table 3. Intensities of homologous and heterologous staining by group A conjugate sorbed with group $C$ cells when mixed with varying amounts of group $C$ antiserum

\begin{tabular}{|c|c|c|c|c|c|c|}
\hline \multirow{2}{*}{ Strain stained } & \multicolumn{6}{|c|}{ Dilution of group $\mathrm{C}$ antiscrum in sorbed group A globulin $(1: 40)$} \\
\hline & $1: 10$ & $1: 40$ & $1: 80$ & $1: 160$ & $1: 320$ & $1: 640$ \\
\hline 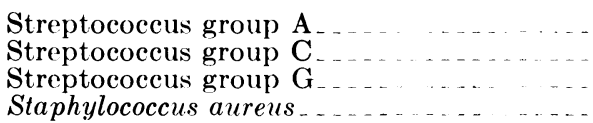 & $\begin{array}{l}4 \\
\pm \\
\pm \\
\pm\end{array}$ & $\begin{array}{r}4 \\
1 \\
\pm \\
1\end{array}$ & $\begin{array}{l}4 \\
2 \\
1 \\
2\end{array}$ & $\begin{array}{l}4 \\
2 \\
2 \\
2\end{array}$ & $\begin{array}{l}4 \\
3 \\
2 \\
3\end{array}$ & 4 \\
\hline
\end{tabular}

Note: Degree of fluorescence designated on $0-4$ scale; \pm-2 , not significant. 


\section{Current Procedure}

Our current procedure for isolation and identification of group A streptococci from throat swabbings follows:

1. The swab is transported to the laboratory, usually by mail, in a collection outfit of which the essential parts (suitably protected) are a sterile cotton swab and a tube containing $1 / 2^{-3 / 4}$ inch of a 1 percent sterile, aqueous agar-agar gel (nutrient free). After the throat has been swabbed, the swab is plunged into the gel and left there during transport. The gel is used only to prevent drying in transit.

2. Upon receipt, the swab is removed from the gel, immediately streaked on the surface of a sheep-blood agar plate, and immersed and retained in about $3 \mathrm{ml}$. of Streptosel broth.

3. The blood plates are incubated in an atmosphere of 90 percent $\mathrm{N}_{2}$ and 10 percent $\mathrm{CO}_{2}$. The broth cultures are incubated aerobically. Both are incubated at $35^{\circ} \mathrm{C}$. for 18 to 24 hours.

4. On the following day, the plates are scanned for beta hemolysis, and the corresponding broth cultures are selected for $\mathrm{FA}$ grouping. Overselection based on any suspicion of beta hemolysis is practiced routinely.

5 . Smears of the selected specimens are prepared by removing the swab from the incubated broth cultures and gently touching the tip to a circled area on a 1 - by 3 -inch microscope slide.

6. When dry, the smears are heat fixed, immersed in buffered saline for 2 minutes, and blotted dry with bibulous paper. The rinsing washes out the broth and restores the $\mathrm{pH}$. Staining is done by covering the smear with the conjugate (modified as described above) for 20 minutes in a moist chamber, rinsing in buffered saline for 10 minutes, blotting dry, and mounting in buffered glycerol under a coverglass.

7. Areas showing beta hemolysis on blood plates of those specimens which fail to show group $A$ by examination of the primary broth culture are fished to broth tubes. After incubation, these are examined for group $\Lambda$ by the FA technique.

8. Appropriate control tests on the reactivity of the FA staining reagent against groups $A$, $\mathrm{C}$, and $\mathrm{G}$ streptococci and coagulase-positive staphylococci are performed daily.

\section{Discussion}

The broth medium of choice for culturing streptococci for FA studies is a matter of individual preference. Laboratories which find it feasible to apply the $\mathrm{FA}$ technique to 2 - to 4-hour broth cultures of throat swabbings will no doubt prefer to use Todd-Hewitt or a similar broth. We prefer overnight incubation for several reasons: (a) a significant number of positive specimens are overlooked with the shorter incubation; $(b)$ the greater numbers of organisms in 18- to 24-hour cultures make microscopic examination less tedious; $(c)$ overnight incubation is more logical than short-time incubation, since specimens are received throughout the day; and $(d)$ our system permits use of a screening procedure (blood agar plate scanning) which reduces the workload.

While Todd-Hewitt broth favors rapid development of streptococci in a few hours, we have found that group A cells are more easily recognized after overnight incubation in Streptosel broth. Larger sized cells, brighter staining, and even more irregular morphology contribute to this easy identification. Although our original choice of Streptosel broth to inhibit growth of staphylococci has been obviated by the inhibition test, we have continued to use it because after 18 - to 24-hour incubation it yields good FA preparations. However, Streptosel broth, if not sterilized strictly according to the manufacturer's specifications, can be inhibitory to streptococci. Selection or development of a less critical broth medium for 18 - to 24 -hour culturing of streptococci for FA staining is a matter for further investigation.

Although we have used the conventional precipitin test for preliminary testing of grouping antiserums prepared in rabbits, it is noteworthy that one such antiserum found lacking in precipitin activity nevertheless yielded a conjugate reactive by the $\mathrm{FA}$ technique in $1: 200$ dilution. At present, we can only speculate as to the reason for this occurrence. However, it does suggest that $\mathrm{FA}$ techniques have a potential not possessed by other serologic test for the investigation of immune responses.

Our rout ine procedures for identifying group A streptococci in throat swabbings are uniquely applicable in a public health laboratory which 
handles large numbers of cultures. It is too time consuming to subject each and every broth culture to FA examination. Parallel blood plates and broth cultures make it possible to cut the labor in half by using the blood plate scan to select broths for FA study. Furthermore, the retention of the swab in the broth culture permits easy preparation of smears without prior centrifugation. We have found that any toxic materials which may be eluted from the swab's wooden applicator during incubation are counteracted by the buffering action of the broth. Of course, adhesives containing phenolic preservatives to bond cotton swabs to the applicator sticks should not be used. Finally, the FA staining reagent we have described will clearly differentiate group $\mathbf{A}$ streptococci from cross-reacting groups with a minimum of effort and, because it also eliminates staphylococcal cross-reactions, it will eliminate the double labor in parallel testing with normal rabbit conjugate.

Undoubtedly, a few broth cultures containing group A streptococci will be missed by the screening procedure. However, in our experience, the number is insignificant. In one typical pilot study, all broths from 1,534 consecutive specimens were examined and the increased productivity observed was 9 specimens (217 specimens positive on $\mathrm{FA}$ examination of all broths, 208 positive on the basis of preselection by blood plate scanning). Thus, the blood plates as indicators of the possible presence of group A streptococci were 95.9 percent reliable. Only 539 of the 1,534 specimens showed any semblance of beta hemolysis on blood plates; hence, FA examination of 995 broth cultures would have been eliminated by relying on the blood plate screen, better than a 60 percent reduction of work. In terms of total specimens, false negative results would have been obtained in only 0.6 percent of the 1,534 specimens by the blood plate scanning procedure.

\section{Summary}

The routine handling of large numbers of throat cultures by the Connecticut State Department of Health laboratories has been simplified by the development and application of a fluorescent antibody (FA) reagent highly specific for group A streptococi and a modification of the laboratories' original culture procedures.

Use of the FA reagent in a one-step inhibition technique has resulted in bright and distinct FA staining of group A streptococci without interference from other streptococcal groups or staphylococci, when present. Sensitivity and specificity of the reagent have been routinely evidenced.

\section{REFERENCES}

(1) Redys, J. J., Ross, M. R., and Borman, E. K. : Inhibition of common antigen fluorescence in grouping streptococci by the fluorescent antibody method. J. Bact. $80: 823-829$ (1960).

(2) Kabat. F. A., and Mayer, M. M.: Experimental immunochemistry. Charles C Thomas, Springfield, Ill., 1948.

(3) Marshall, J. D., Eveland, W. C., and Smith, C. W. : Superiority of fluorescein isothiocyanate (Riggs) for fluorescent antibody technic with a modification of its application. Proc. Soc. Exper. Biol. \& Med. 98: 898-900 (1958).

(4) Moody, M. D., Ellis, E. C., and Updyke, E. L. : Staining bacterial smears with fluorescent antibody. IV. Grouping streptococei with fluorescent antibody. J. Bact. 75: 553-560 (1958).

(5) Oeding, P.: Antigenic properties of Staphylococcus aureus. Bact. Rev. 24: 374-396 (1960).

(6) Cohen, J. O., Cowart, G. S., and Cherry, W. B.: Antibodies against staphylococcus aureus in nonimmunized rabbits. J. Bact. 82:110-114 (1961).

( 7 ) Moody, M. D., Goldman, M., and Thomason, B. M. : Staining bacterial smears with fluorescent antibodies. I. General methods for Malleomyces pseudomallei. J. Bact. 72: 357-361 (1956).

(8) Goldman, M.: Staining Toxoplasma gondii with fluorescein-labeled antibody. II. A new serological test for antibodies to Toxoplasma based upon inhibition of specific staining. J. Exper. Med. 105 : 557-573 (1957). 